The BDJ News section accepts items that include general news, latest research and diary events that interest our readers. Press releases or articles may be edited, and should include a colour photograph if possible. Please direct your correspondence to the News Editor, Arveen Bajaj at the BDJ, 64 Wimpole Street WIG 8YS or by email to bdj@bda.org

\section{New tobacco cessation guide}

The BDA and the Health Development Agency have recently produced a tobacco cessation guide for dentists and their teams.

Helping smokers to stop - a guide for the dental team includes practical information on how to give effective advice on the dangers of tobacco and uses case studies to illustrate how dental practitioners and PCTs are working together to promote tobacco cessation.

Local NHS smoking cessation services have been set up in recent years, and the guide encourages the dental team to refer smokers to these services. Most services offer both one to one and group counselling sessions for smokers who are keen to quit.

Up to 3.5 hours of verifiable CPD will be obtainable by answering the questions listed in the guide, a copy of which has been sent to all BDA members in England as an insert to this issue of the $B D J$.

Copies of the guide can also be downloaded from the British Dental Association website (www.bda.org).

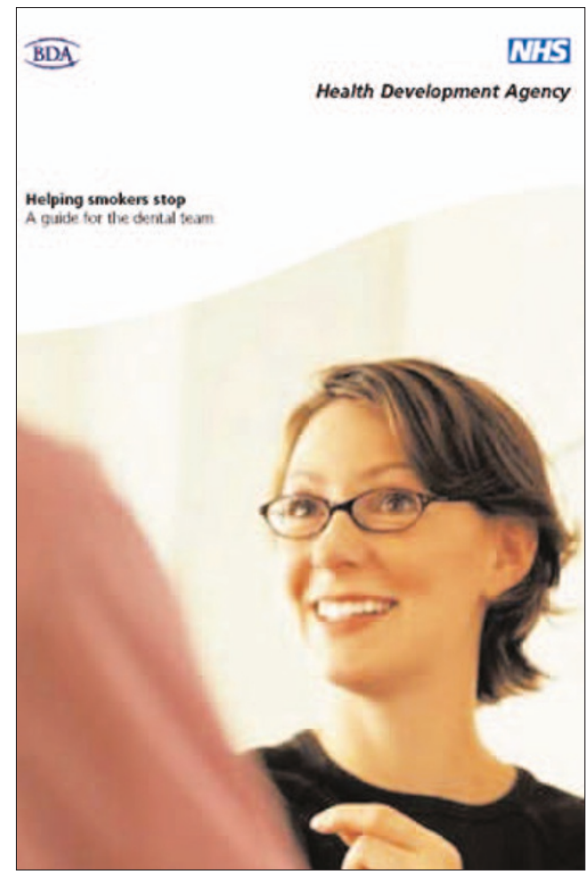

\section{Armed forces joint event held}

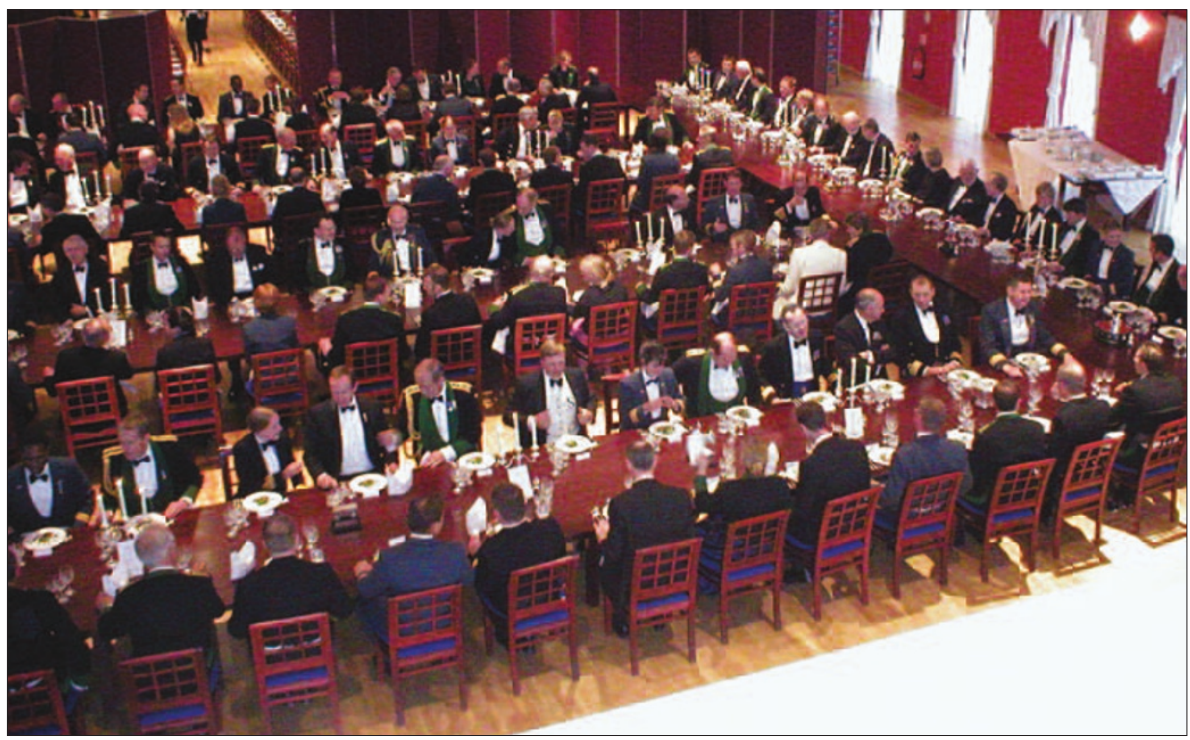

The first joint formal dinner with officers from the Royal Navy Dental Services, the Royal Army Medical Corps, the Royal Army Dental Corps and the Royal Air Force Dental Branch both serving and retired took place recently at the Joint Services Command and Staff College in Shrivenham. The event was held at the conclusion of the annual study day of the Armed Forces Group of the BDA.

\section{Innovative design wins prize}

A student of Napier University has become the winner of the Medical Products category of the Royal Society for the encouragement of Arts, Manufacture and Commerce (RSA) Design Directions Awards.

Katy Buchan won the GlaxoSmithKline Internship worth $£ 7,500$ for her design 'After Dinner Mint' which is a small piece of gum on a stick.

Her aim was to

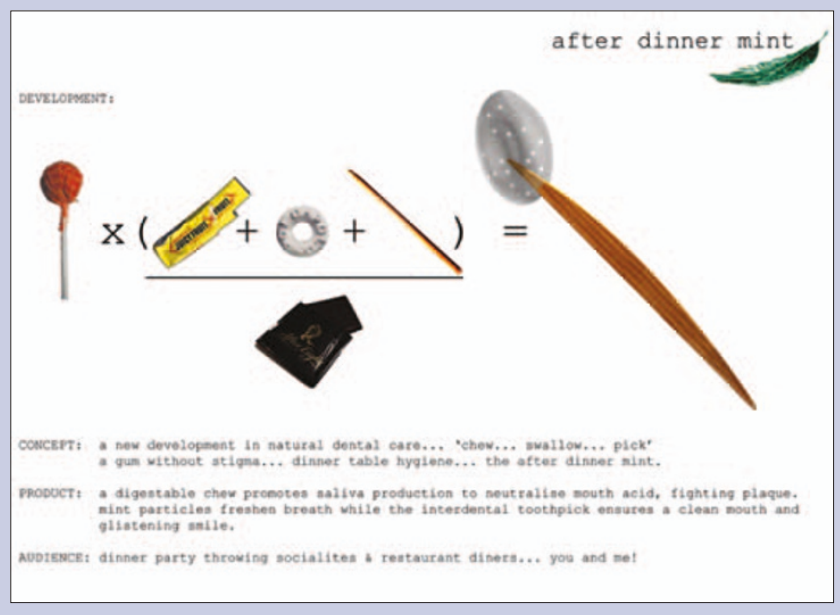

Katy Buchan's winning design 'After Dinner Mint'. develop an oral care product for use after eating. The gum has dental hygiene properties and once finished leaves the stick which can be used as a toothpick. Alan Cook of the University of Salford won the RSA Design Directions Travel Award for redesigning the things that people unconsciously chew, such as bottle caps. His designs included a bottle cap with a fluoride gel dispenser, so that the act of chewing the bottle top could be good for the teeth. 


\section{DIARY}

August 2004

8th Congress of International Congress of Oral Implantologist/Asia Pacific Section \&t 20th International Symposium of the Asian Oral Implant Academy

Date: 27-29.08.04

Venue: The New Otani, Singapore Contact: The ICO/AP-AOIA Meeting Secretariat

Tel: 67343162

Email: singdent@singnet.com.sg http://web.singnet.com.sg/ qualiser/me eting.html

September 2004

IFEA Sixth Endodontic World Congress

Date: 8-11.09.04

Venue: Brisbane Convention and

Exhibition Centre, Queensland, Australia Tel: (0)7 38585599

Email: ifea2004@im.com.au

www.ifea2004.im.com.au

92nd FDI World Dental Congress

Date: 10-13.09.04

Venue: Delhi, India

Tel: +91 1123315834

Email:shastri@tci.co.in

www.tciconferences.com

\section{October 2004}

European Society for Oral Laser

Applications International Laser Conference Date: 7-8.10.04

Venue: Hotel Intercontinental, Abu Dhabi

Tel: +43/1 4051383 ext. 10

Email: h.schulz@medacad.org

\section{Scholarship awarded}

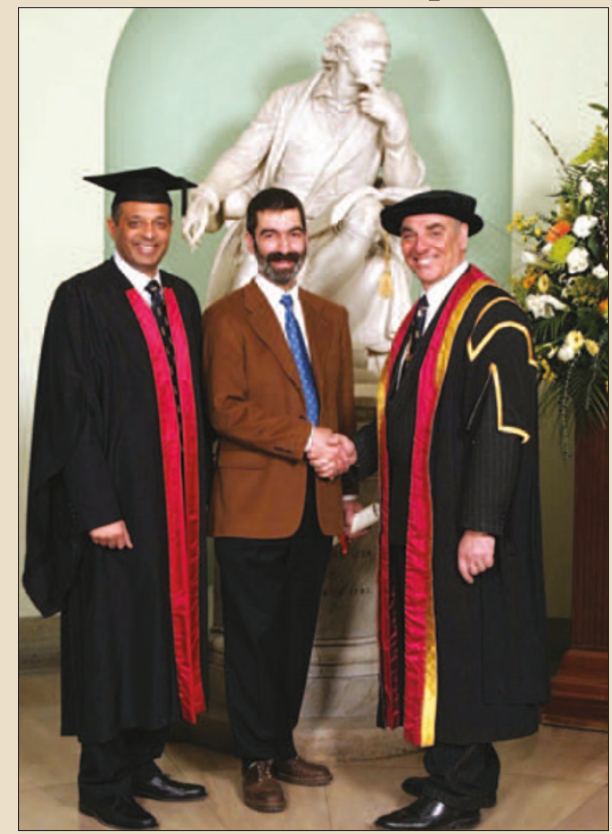

Left to right: Mr Rash Patel, President of the BSGDS, Mr Yann Maidment and Mr Michael Mulcahy, Dean of the FGDP(UK).
Dr Yann Maidment, a general dental practitioner from Edinburgh, has been awarded the British Society for General Dental Surgery (BSGDS) Scholarship Award for 2003 by the Faculty of General Dental Practitioners (UK).

The scholarship is awarded for research in general dental practice and is sponsored by the BSGDS.

Dr Maidment was presented with the award at the Faculty's Diplomates ceremony earlier this year and was given a prize of $£ 2,000$ to support the research programme.

The winning study will be looking at 'Perceptions of success in root canal treatment between patients and dentists'.

The Scholarship is awarded after the presentation of a full protocol supporting the idea of research, and the dental surgeon has two years to complete his research and report.

\section{New Chairman appointed at DVTA}

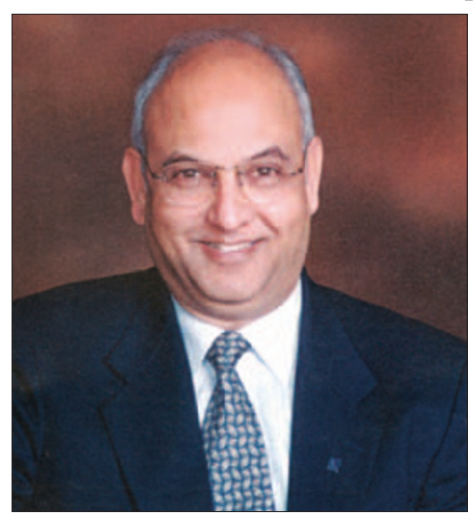

The Dental Vocational Training Authority (DVTA) has recently appointed Dr Rasikkumar Ladwa as Chairman. A GDP in Ealing, West London, Dr Ladwa is currently Vice Dean of the Faculty of General Dental Practitioners (FGDP(UK) an examiner for both the MFGDP and MGDS Diplomas and a postgraduate tutor.

The DVTA is a Special Health Authority which adjudicates applications for dental vocational training numbers on behalf of Primary Care Trusts in England and Wales. It is also responsible for the vocational training curriculum and quality assurance of vocational training schemes in England. 


\section{Top VDPs pick up prizes}
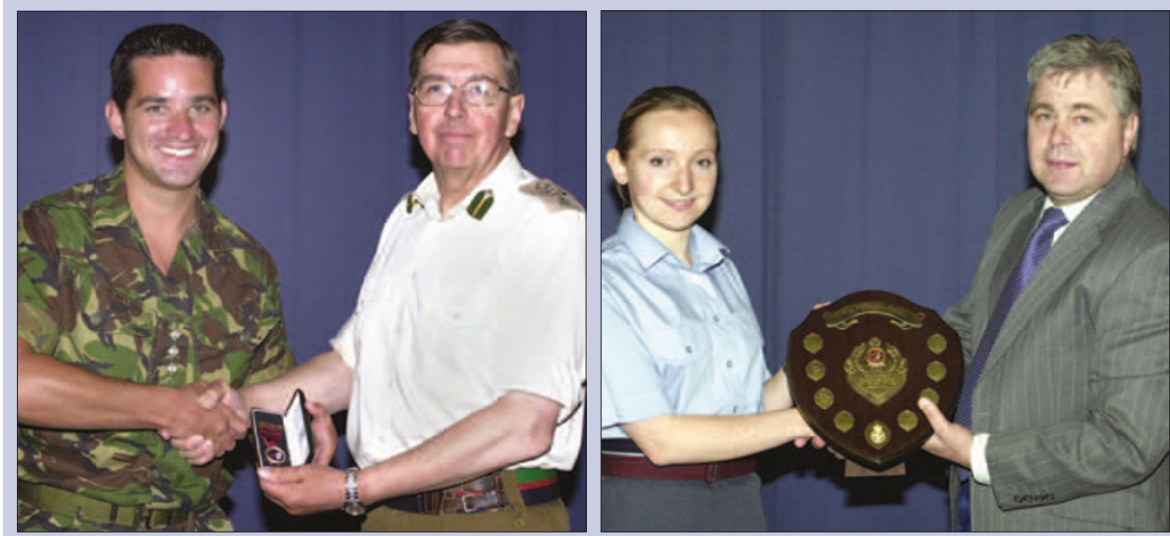

Major General J A Gamon CBE OHDS, Chief Executive of the Defence Dental Agency and

Mr Keith Boyle (right) presents Flight Lieutenant Chairman of the AFG of the BDA, (right) awarding the BDA AFG prize to Captain Richard Lindsay.

Two top vocational dental practitioners from the Defence Dental Agency received awards for their presentations at the recent Annual General Meeting of the Armed Forces Group of the British Dental Association.

The top VDP audit project prize went to Captain Richard Lindsay of the Royal Army Dental Corps for his audit project on the use of antibiotics.

The winner of the Paterson prize went to Flight Lieutenant Izabella Kudanowska of the Royal Air Force Dental Branch for her clinical log diary.

VDPs are required to produce two presentations as part of their vocational training year, one on a clinical case log and the other as part of an audit project.

\section{Orthodontic research recognised}

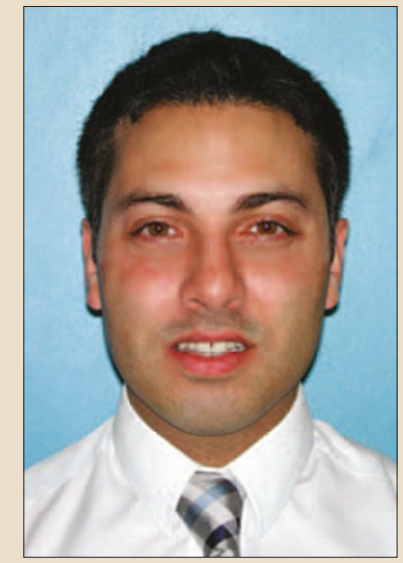

Dr Mark Sayers recently won the Royal Society of Medicine Odontology Section President's Prize for best research presentation.

He is currently an SpR in Orthodontics at GKT Dental Institute, King's College London and presented his MSc research on the development of a measure in regards to patients' expectations of orthodontic treatment.

The winner in each category was given a certificate, a cheque for $£ 100$ and a years Young Fellow Membership of the Society.

The prize is awarded annually and is open to clinicians who have qualified less than twelve years prior to the meeting.

\section{Visiting Professor appointed}

Professor Peter Cleaton-Jones has been appointed visiting Professor in Child Dental Health at the Leeds Dental Institute. He is currently the Head of the MRC Dental Research Institute Unit, University of Witwatersrand, Johannesburg, South Africa.

He will be developing and supervising research related to experimental pulp treatments and also to improve the prognosis for reimplanted traumatically avulsed incisors.

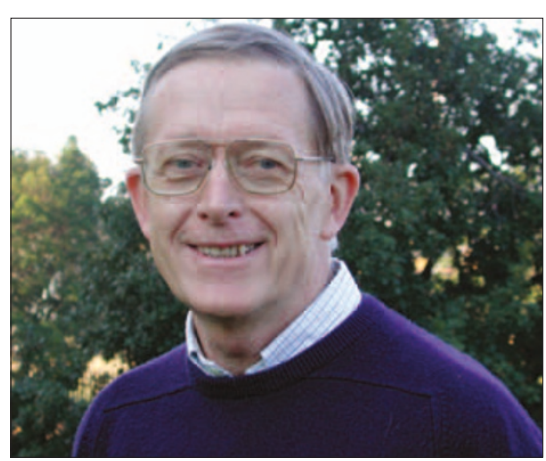

